\title{
Measurement of Peri-Implant Bone Width with and without Metal Artifact Reduction Algorithm Using Two Cone-Beam Computed Tomography Software Programs
}

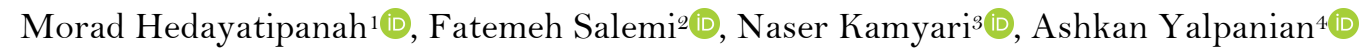

\begin{abstract}
'Department of Periodontics, Faculty of Dentistry, Hamadan University of Medical Sciences, Hamadan, Iran.
2Department of Oral and Maxillofacial Radiology, Faculty of Dentistry, Hamadan University of Medical Sciences, Hamadan, Iran.

${ }^{3}$ Department of Biostatics, Abadan Faculty of Medical Science, Abadan, Iran.

${ }^{4}$ Faculty of Dentistry, Hamadan University of Medical Sciences, Hamadan, Iran.
\end{abstract}

Correspondence: Fatemeh Salemi, Department of Oral and Maxillofacial Radiology, Faculty of Dentistry, Hamadan University of Medical Sciences, Hamadan, Iran. E-mail: dr.fatemehsalemi@yahoo.com

Academic Editor: Wilton Wilney Nascimento Padilha

Received: 24 February 2021 / Review: 25 April 2021 / Accepted: 10 May 2021

How to cite: Hedayatipanah M, Salemi F, Kamyari N, Yalpanian A. Measurement of peri-implant bone width with and without metal artifact reduction algorithm using two cone-beam computed tomography software programs. Pesqui Bras Odontopediatria Clín Integr. 2021; 21:e0050. https://doi.org/10.1590/pboci.2021.118

\footnotetext{
ABSTRACT

Objective: To assess the effect of metal artifact reduction (MAR) algorithm of two cone-beam computed tomography (CBCT) software programs on the accuracy of peri-implant bone width measurements. Material and Methods: This in vitro study evaluated 35 bovine rib bone blocks measuring 8 × $8 \times 11 \mathrm{~mm}$. Titanium implants were inserted in bone blocks and placed in a wax model of mandible. CBCT scans were obtained with ProMax 3D and Cranex 3D CBCT systems with and without the MAR algorithm. The width of buccal and lingual bone plates surrounding the implant was measured on CBCT scans by two observers. The Cronbach's alpha was calculated to assess inter-observer agreement. The area under the curve (AUC), sensitivity and specificity values were calculated and compared. Results: The two observers had an excellent agreement. The accuracy of Cranex 3D was higher than that of ProMax 3D $(\mathrm{p}<0.05)$. Both CBCT systems showed higher accuracy when the MAR algorithm was not used $(\mathrm{p}<0.05)$. Both CBCT systems showed higher accuracy for measuring the width of the lingual plate than buccal plate $(\mathrm{p}<0.05)$. Conclusion: The application of MAR algorithm did not notably increase the measurement accuracy in any CBCT system. Cranex 3D showed generally higher measurement accuracy than ProMax 3D.

Keywords: Cone-Beam Computed Tomography; Dental Implants; Artifacts.
} 


\section{Introduction}

Dental implants are increasingly used for replacement of lost teeth [1,2]. Long-term clinical assessment of dental implants and their supporting structures can provide valuable information regarding the success and failure of implant restorations [3]. The success criteria for implant treatment include the absence of pain and hypersensitivity when in function, no mobility, and limited bone loss not exceeding $0.2 \mathrm{~mm}$ annually after the first year of loading [4]. The level of peri-implant bone is among the critical factors determining the success of dental implants. Inadequate bone volume or quality can compromise the long-term prognosis of dental implants [4].

Periapical or panoramic radiographic modalities are commonly used for the assessment of dental implant status. However, these imaging modalities are two-dimensional and provide two-dimensional images of three-dimensional (3D) structures and suffer from superimposition. Also, they do not have adequately high resolution and can lead to erroneous measurements or misinterpretations [5,6].

The advent of computed tomography (CT) in early 1970 enabled a more accurate assessment of anatomical structures, particularly the calcified structures such as bones and teeth. Nonetheless, long-duration of exposure, high cost, and difficult access to CT scanners led to development of cone-beam computed tomography (CBCT) [5]. The main advantage of CBCT over CT is lower patient radiation dose. At present, CBCT has a higher diagnostic value in dentistry than CT due to the smaller size of the scanner, lower cost, high speed of scanning, resolution $<1 \mathrm{~mm}$, low radiation dose, isotropic voxels, and a stronger image reconstruction software compared with CT. In addition, CBCT enables 3D image reconstruction in crosssectional and panoramic views with high resolution and optimal accuracy [7,8]. However, both CT and CBCT suffer from metal artifacts (mainly related to dental implants), affecting the image quality in 3D image reconstruction [9,10]. Metal artifacts can significantly lower the quality of CBCT images. Thus, some algorithms have been suggested for metal artifact reduction (MAR) in CT and CBCT. The MAR software programs employ different algorithms to eliminate or minimize metal artifacts [11-13].

Radiographic measurement of the width of buccal and lingual bone plates around a dental implant can help in the assessment of implant health as an adjunct to clinical examination. It also enables prompt and early intervention in case of a problem to prevent further bone destruction and eventual implant loss [11-13]. Thus, this study aimed to assess the effect of MAR algorithm of two CBCT software programs on the accuracy of peri-implant bone width measurements.

\section{Material and Methods}

\section{Study Design and Sampling}

This in vitro experimental study evaluated 35 bovine rib bone blocks (due to their similarity to human alveolar bone) measuring $8 \times 8 \times 11 \mathrm{~mm}$ [14]. The sample size was calculated to be 30 according to a previous study [15]. To increase accuracy, 35 samples were included. The bone blocks were kept refrigerated at $4{ }^{\circ} \mathrm{C}$ during the study period to prevent dehydration [14]. The soft tissue residues were removed, and titanium implants (SIC invent AG, Basel, Switzerland) with $4 \mathrm{~mm}$ diameter and $9.5 \mathrm{~mm}$ height were placed in bone blocks such that the distance between the implant and the buccal and lingual surfaces was $2 \mathrm{~mm}$ (Figure1). Also, a plastic mold was fabricated, and the bone blocks were firmly placed in the plastic mold to enhance implant placement. Next, several layers of red dental wax with $2 \mathrm{~mm}$ thickness were used to create a model of mandible. The bone blocks were mounted in this model and underwent CBCT. 


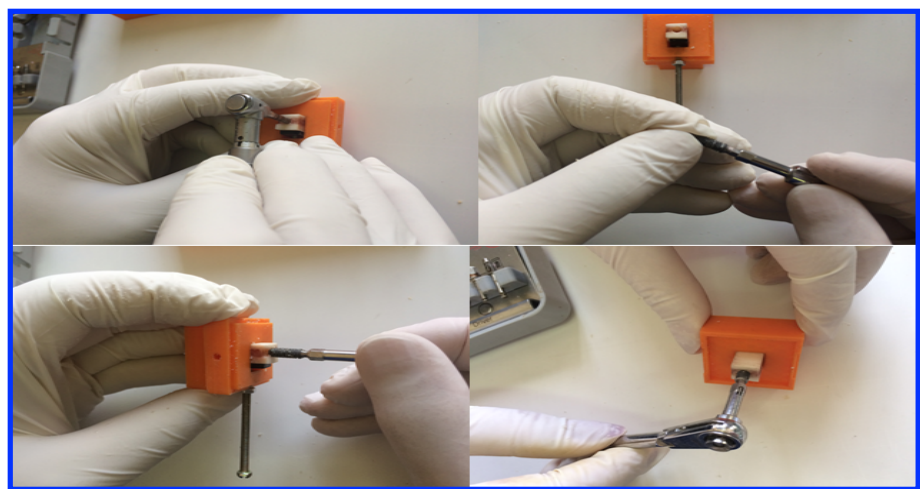

Figure 1. Implant placed in bone block.

Data Collection

CBCT scan were obtained using ProMax 3D (Planmeca, Helsinki, Finland) scanner with the exposure settings of $84 \mathrm{kVp}, 14 \mathrm{~mA}$, and $12 \mathrm{~s}$ time, and Cranex 3D scanner (Soredex, Helsinki, Finland) with the exposure settings of $90 \mathrm{kVp}, 14 \mathrm{~mA}$, and $12 \mathrm{~s}$ time. CBCT scans were obtained in two modes, with and without enabling the MAR algorithm.

The CBCT scans obtained by ProMax 3D were edited and saved in Romexis software version 11.5.0.593, while the CBCT images obtained by Cranex 3D were edited and saved in On-Demand software version 1.0.10.5385. Next, cross-sectional images with $1 \mathrm{~mm}$ slice thickness and $1 \mathrm{~mm}$ slice interval were reconstructed, focusing on the implant center as much as possible. The buccal and lingual bone width was then measured at two points with $2 \mathrm{~mm}$ and $5 \mathrm{~mm}$ distance from the implant platform using the linear measurement tool of the two software programs (Figures 2 to 5 ).

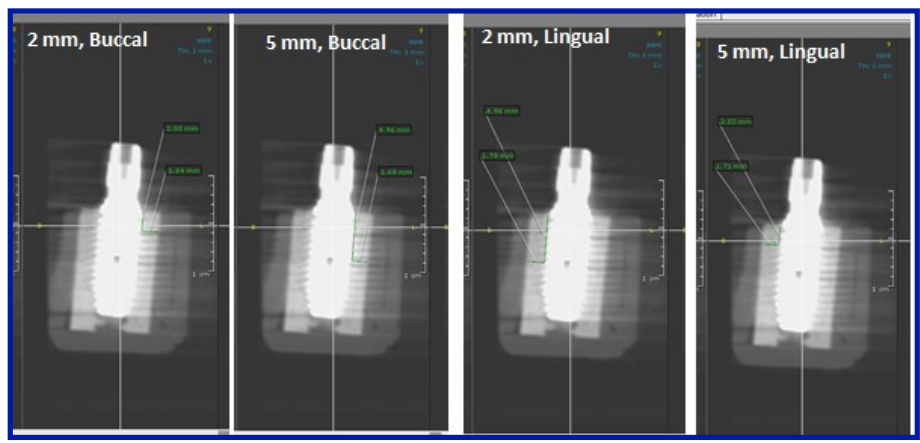

Figure 2. The buccal and lingual bone width measurement at two points with $2 \mathrm{~mm}$ and $5 \mathrm{~mm}$ distance from the implant platform using the linear measurement tool of On-demand software without artifact reduction.

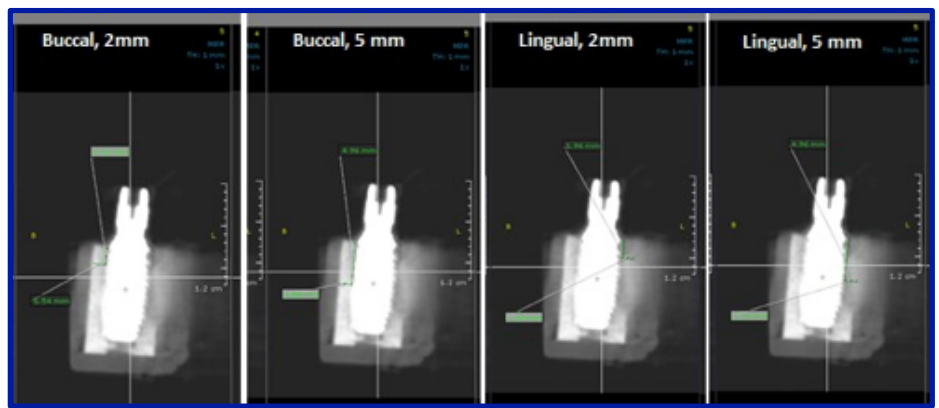

Figure 3. The buccal and lingual bone width measurement at two points with $2 \mathrm{~mm}$ and $5 \mathrm{~mm}$ distance from the implant platform using the linear measurement tool of On-demand software with artifact reduction. 


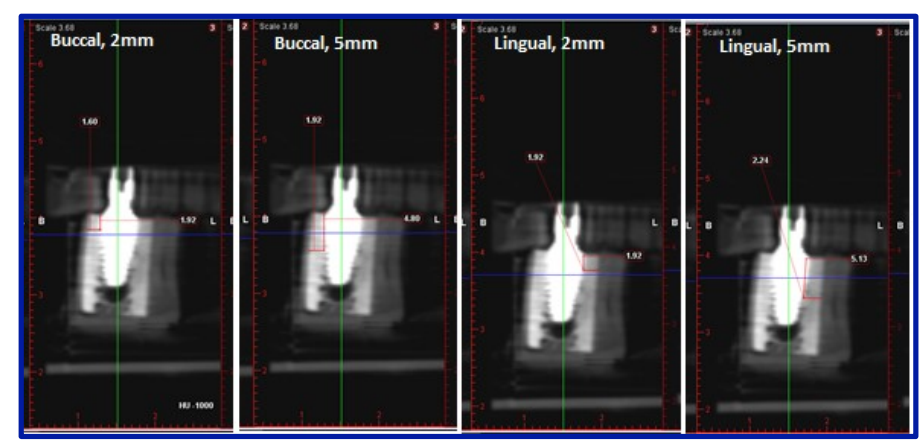

Figure 4. The buccal and lingual bone width measurement at two points with $2 \mathrm{~mm}$ and $5 \mathrm{~mm}$ distance from the implant platform using the linear measurement tool of Romex is software without artifact reduction.

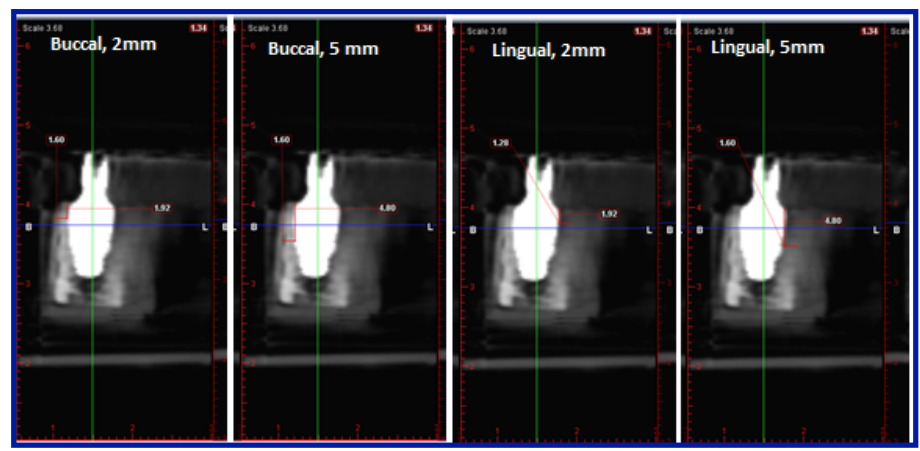

Figure 5. The buccal and lingual bone width measurement at two points with $2 \mathrm{~mm}$ and $5 \mathrm{~mm}$ distance from the implant platform using the linear measurement tool of Romex is software with artifact reduction.

The measured values were then recorded in a checklist [16]. The measurements were made by two observers, namely a senior dental student and a periodontist. The observers were allowed to adjust the brightness and contrast of images to perform measurements on images with the best possible quality. Also, the observation conditions, such as the environmental lighting and computer features, were the same for both observers to obtain more reliable results.

Data Analysis

Data were analyzed using SPSS version 16 and MedCalv version 13. The Cronbach's alpha was calculated to assess the inter-observer agreement (Cronbach's alpha=0.4 indicated poor, 0.4-0.59 indicated moderate, 0.59-0.70 indicated good, and >0.70 indicated excellent agreement) [17]. The mean and standard deviation of the measurements were reported. The receiver operating characteristic (ROC) curve was drawn, and the area under the ROC curve (AUC) was calculated to assess the accuracy of the two CBCT scanners. The accuracy, sensitivity, and specificity values were calculated and reported for the two scanners with and without the MAR algorithm. The level of significance was set at 0.05.

\section{Results}

Table 1 shows the inter-observer agreement for different measurements using Cronbach's alpha. As shown, the two observers had an optimal inter-observer agreement for all measurements.

Table 2 shows the mean buccal and lingual bone width at 2 and $5 \mathrm{~mm}$ distance from the implant platform measured on ProMax 3D and Cranex 3D CBCT scans with and without the MAR algorithm. The results showed that on both ProMax 3D and Cranex 3D CBCT scans, enabling the MAR algorithm resulted in underestimation of bone width compared with no use of MAR. 
Table 1. Inter-observer reliability for different measurements using Cronbach's alpha.

\begin{tabular}{|c|c|c|c|c|c|c|c|}
\hline \multicolumn{4}{|c|}{ ProMax } & \multicolumn{4}{|c|}{ Cranex 3D } \\
\hline \multicolumn{2}{|c|}{ Without MAR } & \multicolumn{2}{|c|}{ With MAR } & \multicolumn{2}{|c|}{ Without MAR } & \multicolumn{2}{|c|}{ With MAR } \\
\hline Buccal & Lingual & Buccal & Lingual & Buccal & Lingual & Buccal & Lingual \\
\hline 0.981 & 1.0 & 1.0 & 0.984 & 0.798 & 0.802 & 0.887 & 0.9 \\
\hline
\end{tabular}

Table 2. Mean buccal and lingual bone width at $2 \mathrm{~mm}$ and $5 \mathrm{~mm}$ from the implant platform on ProMax 3D and Cranex 3D CBCT scans with and without the MAR algorithm.

\begin{tabular}{|c|c|c|c|c|c|c|c|c|c|c|c|c|c|c|c|}
\hline \multicolumn{8}{|c|}{ ProMax } & \multicolumn{8}{|c|}{ Cranex 3D } \\
\hline \multicolumn{4}{|c|}{ Without MAR } & \multicolumn{4}{|c|}{ With MAR } & \multicolumn{4}{|c|}{ Without MAR } & \multicolumn{4}{|c|}{ With MAR } \\
\hline \multicolumn{2}{|c|}{ Lingual } & \multicolumn{2}{|c|}{ Buccal } & \multicolumn{2}{|c|}{ Lingual } & \multicolumn{2}{|c|}{ Buccal } & \multicolumn{2}{|c|}{ Lingual } & \multicolumn{2}{|c|}{ Buccal } & \multicolumn{2}{|c|}{ Lingual } & \multicolumn{2}{|c|}{ Buccal } \\
\hline $2 \mathrm{~mm}$ & $5 \mathrm{~mm}$ & $2 \mathrm{~mm}$ & $5 \mathrm{~mm}$ & $2 \mathrm{~mm}$ & $5 \mathrm{~mm}$ & $2 \mathrm{~mm}$ & $5 \mathrm{~mm}$ & $2 \mathrm{~mm}$ & $5 \mathrm{~mm}$ & $2 \mathrm{~mm}$ & $5 \mathrm{~mm}$ & $2 \mathrm{~mm}$ & $5 \mathrm{~mm}$ & $2 \mathrm{~mm}$ & $5 \mathrm{~mm}$ \\
\hline 1.76 & 1.87 & 1.75 & 1.83 & 1.74 & 1.74 & 1.51 & 1.52 & 1.90 & 1.96 & 1.93 & 2.01 & 1.74 & 1.84 & 1.65 & 1.70 \\
\hline \pm & \pm & \pm & \pm & \pm & \pm & \pm & \pm & \pm & \pm & \pm & \pm & \pm & \pm & \pm & \pm \\
\hline 0.22 & 0.26 & 0.51 & 0.52 & 0.29 & 0.29 & 0.61 & 0.61 & 0.19 & 0.21 & 0.18 & 0.19 & 0.41 & 0.46 & 0.26 & 1.28 \\
\hline
\end{tabular}

The difference in measurements made at $2 \mathrm{~mm}$ and $5 \mathrm{~mm}$ distance was not significant ( $\mathrm{p}>0.05)$. Thus, considering the small sample size, the mean bone width values at 2 and $5 \mathrm{~mm}$ distances were merged and the mean values were reported as the mean buccal and lingual bone width (Table 3 ).

Table 3. Mean buccal and lingual bone width.

\begin{tabular}{|c|c|c|c|c|c|c|c|c|}
\hline & \multicolumn{4}{|c|}{ Cranex 3D } & \multicolumn{4}{|c|}{ ProMax 3D } \\
\hline & \multicolumn{2}{|c|}{ Presence of MAR } & \multicolumn{2}{|c|}{ Absence of MAR } & \multicolumn{2}{|c|}{ Presence of MAR } & \multicolumn{2}{|c|}{ Absence of MAR } \\
\hline & Buccal & Lingual & Buccal & Lingual & Buccal & Lingual & Buccal & Lingual \\
\hline Mean & $1.68 \pm 0.27$ & $1.79 \pm 0.44$ & $1.97 \pm 0.19$ & $1.93 \pm 0.20$ & $1.52 \pm 0.61$ & $1.74 \pm 0.29$ & $1.79 \pm 0.51$ & $1.82 \pm 0.25$ \\
\hline p-value* & 0.441 & 0.340 & 0.075 & 0.214 & 0.945 & 0.988 & 0.518 & 0.060 \\
\hline
\end{tabular}

Figures 6 and 7 show the AUC for the width of buccal and lingual bone plates measured by the two observers on Cranex 3D and ProMax 3D CBCT scans. Also, Tables 4 and 5 show the AUC calculated by the first and second observers. Comparison of the two observers revealed a difference only in use of Romex is software without the MAR algorithm for measurement of the thickness of buccal bone plate, which was significant for the first observer and insignificant for the second observer.

Table 4. Area Under ROC curve determined by the first observer.

\begin{tabular}{ccccccccc}
\hline & \multicolumn{4}{c}{ Cranex 3D } & \multicolumn{4}{c}{ ProMax 3D } \\
& \multicolumn{2}{c}{ Presence of MAR } & Absence of MAR & Presence of MAR & \multicolumn{2}{c}{ Absence of MAR } \\
& Buccal & Lingual & Buccal & Lingual & Buccal & Lingual & Buccal & Lingual \\
\hline $\mathrm{AUC}^{1}$ & 0.608 & 0.797 & 0.9 & 0.937 & 0.504 & 0.705 & 0.825 & 0.999 \\
$\mathrm{SE}^{2}$ & 0.093 & 0.059 & 0.04 & 0.029 & 0.145 & 0.082 & 0.094 & 0.001 \\
$95 \% \mathrm{CI}^{3}$ & $0.48-0.72$ & $0.68-0.88$ & $0.59-0.80$ & $0.85-0.98$ & $0.38-0.62$ & $0.58-0.80$ & $0.71-0.90$ & $0.94-1.0$ \\
Z Statistic & 1.151 & 5.002 & 9.919 & 14.68 & 0.026 & 2.47 & 3.44 & 423.55 \\
p-value & 0.249 & $<0.0001$ & $<0.0001$ & $<0.0001$ & 0.98 & 0.013 & 0.0006 & $<0.0001$ \\
\hline
\end{tabular}

${ }^{1}$ Area Under ROC Curve; ${ }^{2}$ Standard Error; ${ }^{3}$ Confidence Interval.

Table 5. AUC determined by the second observer.

\begin{tabular}{|c|c|c|c|c|c|c|c|c|}
\hline & \multicolumn{4}{|c|}{ Cranex 3D } & \multicolumn{4}{|c|}{ ProMax 3D } \\
\hline & \multicolumn{2}{|c|}{ Presence of MAR } & \multicolumn{2}{|c|}{ Absence of MAR } & \multicolumn{2}{|c|}{ Presence of MAR } & \multicolumn{2}{|c|}{ Absence of MAR } \\
\hline & Buccal & Lingual & Buccal & Lingual & Buccal & Lingual & Buccal & Lingual \\
\hline $\mathrm{AUC}^{1}$ & 0.591 & 0.797 & 0.9 & 0.917 & 0.557 & 0.751 & 0.729 & 0.934 \\
\hline $\mathrm{SE}^{2}$ & 0.097 & 0.059 & 0.04 & 0.0351 & 0.101 & 0.081 & 0.126 & 0.056 \\
\hline $95 \% \mathrm{CI}^{3}$ & $0.46-0.70$ & $0.68-0.88$ & $0.59-0.80$ & $0.82-0.97$ & $0.45-0.69$ & $0.63-0.84$ & $0.61-0.82$ & $0.54-0.98$ \\
\hline Z Statistic & 0.929 & 5.002 & 9.919 & 11.90 & 0.76 & 3.09 & 1.81 & 7.66 \\
\hline p-value & 0.352 & $<0.0001$ & $<0.0001$ & $<0.0001$ & 0.447 & 0.002 & 0.069 & $<0.0001$ \\
\hline
\end{tabular}

${ }^{1}$ Area Under ROC Curve; ${ }^{2}$ Standard Error; ${ }^{3}$ Confidence Interval. 


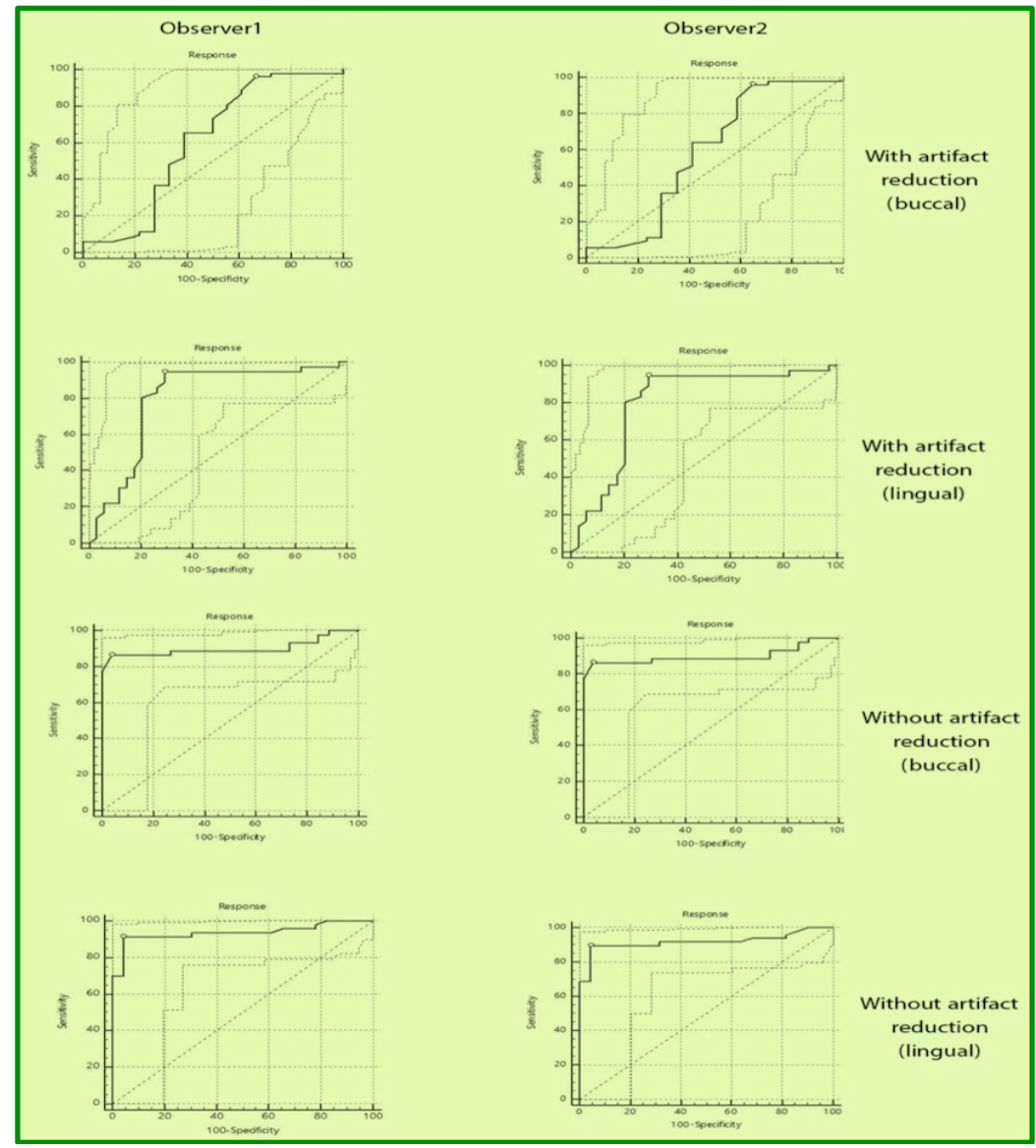

Figure 6. AUC for the width of buccal and lingual bone plates measured by the two observers on Cranex 3D CBCT scans.

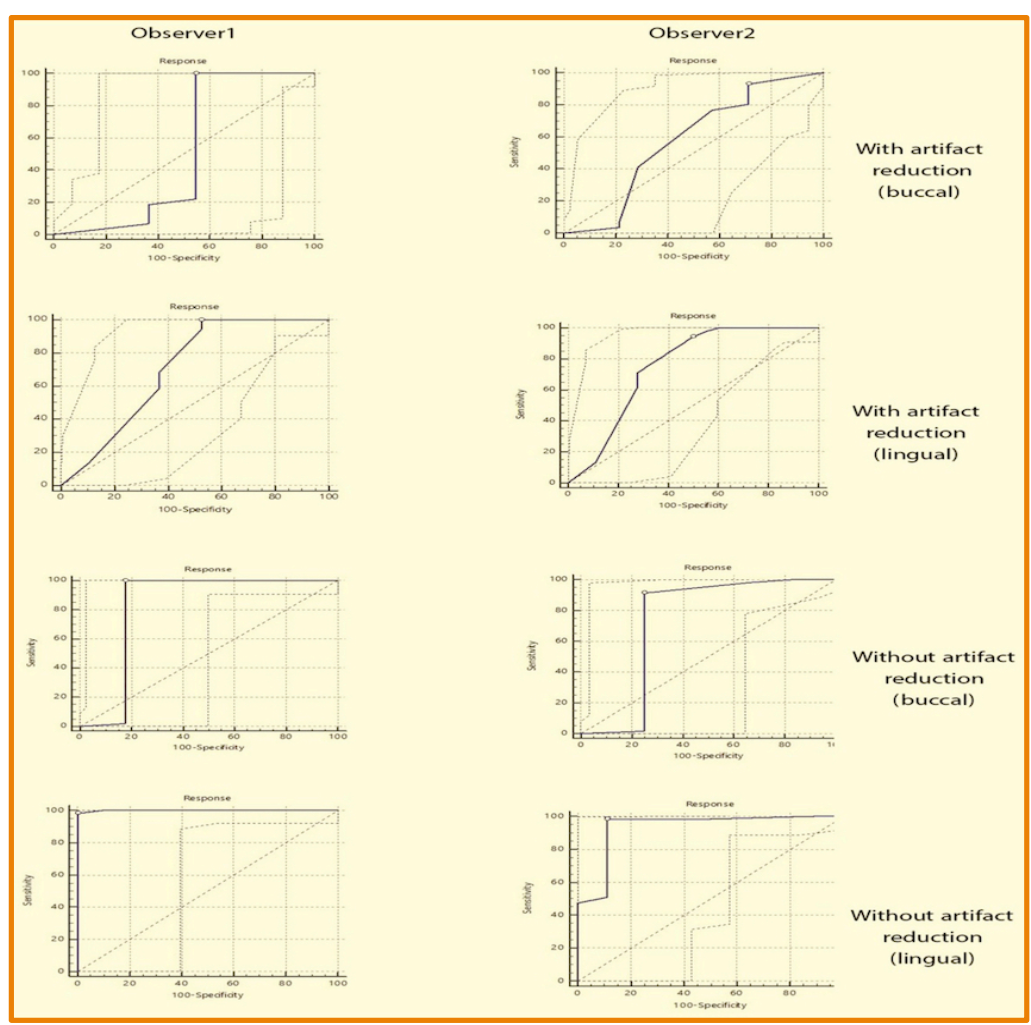

Figure 7. AUC for the width of buccal and lingual bone plates measured by the two observers on ProMax 3D CBCT scans. 
Tables 6 and 7 show the sensitivity and specificity of Cranex 3D and ProMax 3D CBCT scans by the first and second observers. As shown, the sensitivity of both scanners in use of MAR algorithm increased except for the measurement of lingual bone plate by the second observer on ProMax 3D scans. Comparison of the two scanners revealed that ProMax 3D had higher sensitivity except for measurements made by the second observer in use of MAR algorithm. The results of the two observers were in agreement with each other. Comparison of buccal and lingual bone plates revealed that the sensitivity for both measurements was the same; however, the specificity for measurement of buccal plate thickness was lower than that for lingual plate except in the use of Cranex 3D without the MAR algorithm.

Table 6. Sensitivity and specificity of Cranex 3D and ProMax 3D CBCT scans by the first observer.

\begin{tabular}{ccccccccc} 
& \multicolumn{4}{c}{ Cranex 3D } & \multicolumn{4}{c}{ ProMax 3D } \\
& \multicolumn{1}{c}{ Presence of MAR } & \multicolumn{2}{c}{ Absence of MAR } & \multicolumn{2}{c}{ Presence of MAR } & \multicolumn{2}{c}{ Absence of MAR } \\
& Buccal & Lingual & Buccal & Lingual & Buccal & Lingual & Buccal & Lingual \\
\hline A. Cri. ${ }^{1}$ & $\geq 2$ & $\geq 1.96$ & $\geq 2$ & $\geq 1.98$ & $\geq 1.95$ & $\geq 1.95$ & $\geq 1.95$ & $\geq 1.95$ \\
Sen. $^{2}$ & 96.15 & 94.44 & 86.36 & 91.49 & 100.0 & 100.0 & 100.0 & 100.0 \\
Spec. $^{3}$ & 33.33 & 70.59 & 96.15 & 95.65 & 45.45 & 47.37 & 82.35 & 100.0 \\
\hline
\end{tabular}

${ }^{1}$ Associated Criterion; ${ }^{2}$ Sensitivity; ${ }^{3}$ Specificity.

Table 7. Sensitivity and specificity of Cranex 3D and ProMax 3D CBCT scans by the second observer.

\begin{tabular}{ccccccccc} 
& \multicolumn{4}{c}{ Presence of MAR } & \multicolumn{2}{c}{ Absence of MAR } & \multicolumn{4}{c}{ Presence of MAR } & \multicolumn{2}{c}{ Absence of MAR } \\
& Buccal & Lingual & Buccal & Lingual & Buccal & Lingual & Buccal & Lingual \\
\hline A. Cri. $^{1}$ & $\geq 2$ & $\geq 1.96$ & $\geq 2$ & $\geq 1.98$ & $\geq 1.95$ & $\geq 1.92$ & $\geq 1.95$ & $\geq 2.02$ \\
Sen. $^{2}$ & 96.23 & 94.44 & 86.36 & 89.58 & 92.86 & 94.23 & 91.38 & 98.36 \\
Spec. $^{3}$ & 35.29 & 70.59 & 96.15 & 95.45 & 28.57 & 50.0 & 75.0 & 88.89 \\
\hline
\end{tabular}

${ }^{1}$ Associated Criterion; ${ }^{2}$ Sensitivity; ${ }^{3}$ Specificity.

\section{Discussion}

This study aimed to assess the effect of MAR algorithm of two CBCT software programs on the accuracy of peri-implant bone width measurements. Some CBCT scanners such as ProMax 3D allow the users to enable MAR algorithm during image reconstruction. By doing so, 3D information is recalculated, and all areas (voxels) over a certain threshold of gray value are eliminated [9,10].

The current results showed maximum mean width in the buccal bone plate in use of Cranex 3D without the MAR algorithm, while minimum mean width was in the buccal plate in use of ProMax $3 \mathrm{D}$ with the MAR algorithm. Comparison of the two scanners indicated maximum accuracy in measurement of lingual bone width on ProMax CBCT scans without the MAR algorithm followed by the measurement of lingual bone plate on Cranex 3D scans without the MAR algorithm. Minimum accuracy was noted in measurement of buccal bone width on ProMax scans with the MAR algorithm. Measuring the AUC revealed that, in general, Cranex 3D had higher accuracy than ProMax 3D except for measurement of lingual bone width without the MAR algorithm. Also, both scanners had higher accuracy in the absence of the MARalgorithm. Moreover, the accuracy of measuring the lingual bone width was higher than buccal bone width in use of both scanners. ProMax 3D had higher sensitivity than Cranex 3D both with/without the MAR algorithm, while Cranex 3D had higher specificity. Minimum specificity belonged to ProMax 3D with the MAR algorithm for measurement of buccal plate width. It should be noted that the exposure parameters were the same for both scanners except for voltage, which was $84 \mathrm{kVp}$ for ProMax $3 \mathrm{D}$ and $90 \mathrm{kVp}$ for Cranex 3D. 
Studies on the effect of MAR algorithms on the accuracy of peri-implant bone measurements are limited. Bohner et al. [18] measured the thickness of peri-implant bone at three points using Care Stream 9300 andR100 Vera view CBCT scanners and reported no significant difference in the accuracy of the two scanners for this purpose, which was in line with our results. Although MAR algorithms could not improve the quality of CBCT scans in our study, many manufacturers have recommended them to improve the quality of images [19,20]. Kamburoğlu et al. [16] evaluated the peri-implant buccal bone on ProMax 3D CBCT scans with and without the MAR algorithm and reported that MAR did not improve the quality of CBCT scans, in agreement with our results. Similarly, Parsa et al. [12] evaluated the quality of images of peri-implant bone with and without the MAR algorithm and reported that MAR did not improve the quality of images.

Bechara et al. [21] reported that application of MAR algorithm decreased image accuracy for detection of root fracture. Despite different methodology, their results confirmed our findings. Also, deAzevedo-Vaz et al. [4] demonstrated that application of MAR did not improve the diagnostic accuracy of CBCT images for detection of fenestration and dehiscence defects. Vasconcelos et al. [22] used the MAR algorithm in four CBCT scanners for detection of procedural defects in endodontic treatment and reported that application of MAR algorithm did not improve the diagnostic quality of images.

Decreased image quality can be attributed to beam hardening, which cannot be eliminated even by using the MAR algorithms. When the X-ray beam passes through an object, low-energy photons are absorbed in greater amounts than high-energy photons; this phenomenon is referred to as beam hardening [9,23,24] and occurs in high-density objects [9,23]. It occurs in all CBCT systems [23] and leads to generation of cup and beam hardening artifacts attributed to the non-linear attenuation of X-ray beam [25].

Cremonini et al. [26] indicated that the effect of metal artifacts of multi-slice computed tomography on measurement of bone width and height was not significant. In contrast to our findings, they showed low sensitivity of CBCT scans for evaluation of peri-implant bone, while in our study, both CBCT scanners had relatively high sensitivity for this purpose. However, the specificity of images was low in our study, especially when the MAR algorithm was used. Difference between the results of the two studies can be due to the use of different CBCT scanners with different exposure parameters. Razavi et al. [27] used two CBCT scanners to measure the thickness of peri-implant bone and showed that iCAT NG did not have high accuracy for this purpose while Accuitomo 3D60 had much higher accuracy. The iCAT NG CBCT scanner has a lower resolution, which explains its lower accuracy. Also, in contrast to our study, they used different exposure parameters for each CBCT scanner. In our study, ProMax 3D had higher sensitivity but lower diagnostic accuracy than Cranex 3D. In line with our findings, Kajan et al. [28] and de Rezende Barbosa et al. [29] reported inefficacy of MAR algorithms for detection of vertical root fracture.

Type of CBCT scanner has a significant effect on the diagnostic accuracy of images. Differences between CBCT scanners are mainly attributed to their resolution. Similar to our study, Vasconcelos et al. [22] used Cranex 3D scanner and showed optimal accuracy of images. Some others have reported optimal sensitivity of ProMax 3D for assessment of peri-implant bone [16,30]. However, most available studies on the efficacy of CBCT images for assessment of peri-implant bone, including ours, have an in vitro design and suffer from the limitations of in vitro studies. The clinical setting cannot be well simulated in vitro. Thus, the results cannot be reliably generalized to the clinical setting. Clinical studies are required to obtain more reliable results. Also, future studies should use different CBCT scanners with variable voxel sizes and different exposure parameters for such measurements. 


\section{Conclusion}

The application of MAR algorithm did not significantly increase the measurement accuracy in both CBCT systems. However, Cranex 3D showed generally higher measurement accuracy than ProMax 3D, except for measurement of lingual bone width without the MAR algorithm. Also, the accuracy of measuring the lingual bone width was higher than buccal bone width in both scanners.

\section{Authors' Contributions

\begin{tabular}{|c|c|c|}
\hline MH & https://orcid.org/0000-0003-1459-0964 & $\begin{array}{l}\text { Conceptualization, Methodology, Formal Analysis, Investigation, Writing - Original Draft and } \\
\text { Writing - Review and Editing. }\end{array}$ \\
\hline FS & https://orcid.org/0000-0002-0534-3446 & $\begin{array}{l}\text { Conceptualization, Methodology, Formal Analysis, Investigation, Writing - Original Draft and } \\
\text { Writing - Review and Editing. }\end{array}$ \\
\hline NK & https://orcid.org/0000-0002-5209-8324 & $\begin{array}{l}\text { Conceptualization, Methodology, Formal Analysis, Investigation, Writing - Original Draft and } \\
\text { Writing - Review and Editing. }\end{array}$ \\
\hline AY & https://orcid.org/0000-0001-6424-183X & $\begin{array}{l}\text { Conceptualization, Methodology, Formal Analysis, Investigation, Writing - Original Draft and } \\
\text { Writing - Review and Editing. }\end{array}$ \\
\hline
\end{tabular}

\section{Financial Support}

None.

\section{Conflict of Interest}

The authors declare no conflicts of interest.

\section{Data Availability}

The data used to support the findings of this study can be made available upon request to the corresponding author.

\section{References}

[1] Goodman SB, Yao Z, Keeney M, Yang F. The future of biologic coatings for orthopaedic implants. Biomaterials 2013; 34(13):3174-83. https://doi.org/10.1016/j.biomaterials.2013.01.074

[2] Manivasagam G, Dhinasekaran D, Rajamanickam A. Biomedical implants: corrosion and its prevention - a review. Recent patents on corrosion science. Recent Patents Corros Sci 2010; 2:40-54. https://doi.org/10.2174/1877610801002010040

[3] Bittar-Cortez JA, Passeri LA, de Almeida SM, Haiter-Neto F. Comparison of peri-implant bone level assessment in digitized conventional radiographs and digital subtraction images. Dentomaxillofac Radiol 2006; 35(4):258-62. https://doi.org/10.1259/dmfr/84778143.

[4] de-Azevedo-Vaz SL, Peyneau PD, Ramirez-Sotelo LR, de Faria Vasconcelos K, Campos PS, Haiter-Neto F. Efficacy of a cone beam computed tomography metal artifact reduction algorithm for the detection of peri-implant fenestrations and dehiscences. Oral Sur Oral Med Oral Pathol Oral Radiol 2016; 121(5):550-6. https://doi.org/10.1016/j.oooo.2016.01.013

[5] Chan HL, Misch K, Wang HL. Dental imaging in implant treatment planning. Implant Dent 2010; 19(4):288-98. https://doi.org/10.1097/ID.obo13e3181e59ebd

[6] Vandenberghe B, Jacobs R, Bosmans H. Modern dental imaging: a review of the current technology and clinical applications in dental practice. Eur Radiol 2010; 20(11):2637-55. https://doi.org/10.1007/s00330-010-1836-1

[7] De Vos W, Casselman J, Swennen GR. Cone-beam computerized tomography (CBCT) imaging of the oral and maxillofacial region: a systematic review of the literature. Int J Oral Maxillofac Surg 2009; 38(6):609-25. https://doi.org/10.1016/j.ijom.2009.02.028

[8] Quereshy FA, Savell TA, Palomo JM. Applications of cone beam computed tomography in the practice of oral and maxillofacial surgery J Oral Maxillofac Surg 2008; 66(4):791-6. https://doi.org/10.1016/j.joms.2007.11.018

[9] Schulze RK, Berndt D, d'Hoedt B. On cone-beam computed tomography artifacts induced by titanium implants. Clin Oral Implants Res 2010; 21(1):100-7. https://doi.org/10.1111/j.1600-0501.2009.01817.x

[10] Fiala TG, Novelline RA, Yaremchuk MJ. Comparison of CT imaging artifacts from craniomaxillofacial internal fixation devices. Plast Reconstr Surg 1993; 92(7):1227-32.

[11] Bechara BB, Moore WS, McMahan CA, Noujeim M. Metal artefact reduction with cone beam CT: an in vitro study. Dentomaxillofac Radiol 2012; 41(3):248-53. https://doi.org/10.1259/dmfr/80899839 
[12] Parsa A, Ibrahim N, Hassan B, Syriopoulos K, van der Stelt P. Assessment of metal artefact reduction around dental titanium implants in cone beam CT. Dentomaxillofac Radiol 2014; 43(7):20140019. https://doi.org/10.1259/dmfr.20140019

[13] Veldkamp WJ, Joemai RM, van der Molen AJ, Geleijns J. Development and validation of segmentation and interpolation techniques in sinograms for metal artifact suppression in CT. Med phys 2010; 37(2):620-8. https://doi.org/10.1118/1.3276777

[14] Misch KA, Yi ES, Sarment DP. Accuracy of cone beam computed tomography for periodontal defect measurements. J Periodontol 2006; 77(7):1261-6. https://doi.org/10.1902/jop.2006.050367

[15] Wakoh M, Harada T, Otonari T, Otonari-Yamamoto M, Ohkubo M, Kousuge Y, et al. Reliability of linear distance measurement for dental implant length with standardized periapical radiographs. Bull Tokyo Dent Coll 2006; 47(3):105-15. https://doi.org/10.2209/tdcpublication.47.105

[16] Kamburoğlu K, Kolsuz E, Murat S, Eren H, Yüksel S, Paksoy CS. Assessment of buccal marginal alveolar periimplant and periodontal defects using a cone beam CT system with and without the application of metal artefact reduction mode. DentomaxillofacRadiol 2013; 42(8):20130176. https://doi.org/10.1259/dmfr.20130176

[17] Cohen J. A coefficient of agreement for nominal scales. Educ Psychol Meas 1960; 20:37-46. https://doi.org/10.1177/001316446002000104

[18] Bohner LO, Tortamano P, Marotti J. Accuracy of linear measurements around dental implants by means of cone beam computed tomography with different exposure parameters. Dentomaxillofac Radiol 2017; 46(5):20160377. https://doi.org/10.1259/dmfr.20160377

[19] Mahnken AH, Raupach R, Wildberger JE, Jung B, Heussen N, Flohr TG, et al. A new algorithm for metal artifact reduction in computed tomography: in vitro and in vivo evaluation after total hip replacement. Invest Radiol 2003; 38(12):769-75. https://doi.org/10.1097/01.rli.0000086495.96457.54

[20] Robertson DD, Weiss PJ, Fishman EK, Magid D, Walker PS. Evaluation of CT techniques for reducing artifacts in the presence of metallic orthopedic implants. J Comput Assist Tomogr 1988; 12(2):236-41. https://doi.org/10.1097/00004728-198803000-00012

[21] Bechara B, Alex McMahan C, Moore WS, Noujeim M, Teixeira FB, Geha H. Cone beam CT scans with and without artefact reduction in root fracture detection of endodontically treated teeth. Dentomaxillofac Radiol 2013; 42(5):20120245. https://doi.org/10.1259/dmfr.20120245

[22] Vasconcelos KD, Nicolielo LF, Nascimento MC, Haiter-Neto F, Bóscolo FN, Van Dessel J, et al. Artifact expression associated with several cone-beam computed tomographic machines when imaging root filled teeth. Int Endod J 2015; 48(10):994-1000. https://doi.org/10.1111/iej.12395

[23] Esmaeili F, Johari M, Haddadi P, Vatankhah M. Beam hardening artifacts: comparison between two cone beam computed tomography scanners. J Dent Res Dent Clin Dent Prospects 2012; 6(2):49. https://doi.org/10.5681/joddd.2012.011

[24] Naitoh M, Saburi K, Gotoh K, Kurita K, Ariji E. Metal artifacts from posterior mandibular implants as seen in CBCT. Impl Dent 2013; 22(2):151-4. https://doi.org/10.1097/ID.obo13e318284aee2

[25] Zhang Y, Zhang L, Zhu XR, Lee AK, Chambers M, Dong L. Reducing metal artifacts in cone-beam CT images by preprocessing projection data. Int J Radiat Oncol Biol Phys 2007; 67(3):924-32. https://doi.org/10.1016/j.ijrobp.2006.09.045

[26] Cremonini CC, Dumas M, Pannuti CM, Neto JB, Cavalcanti MG, Lima LA. Assessment of linear measurements of bone for implant sites in the presence of metallic artefacts using cone beam computed tomography and multislice computed tomography. Clin Oral Implants Res 2011; 4O(8):845-50. https://doi.org/10.1007/s11547-015-0496-2

[27] Razavi T, Palmer RM, Davies J, Wilson R, Palmer PJ. Accuracy of measuring the cortical bone thickness adjacent to dental implants using cone beam computed tomography. Clin Oral Implants Res 2010; 21(7):718-25. https://doi.org/10.1111/j.1600-0501.2009.01905.x

[28] Kajan ZD, Taramsari M, Fard NK, Khaksari F, Hamidi FM. The efficacy of metal artifact reduction mode in conebeam computed tomography images on diagnostic accuracy of root fractures in teeth with intracanal posts. Iran Endod J 2018; 13(1):47. https://doi.org/10.22037/iej.v13i1.17352

[29] de Rezende Barbosa GL, Sousa Melo SL, Alencar PN, Nascimento MC, Almeida SM. Performance of an artefact reduction algorithm in the diagnosis of in vitro vertical root fracture in four different root filling conditions on CBCT images. Int Endod J 2016; 49(5):500-8. https://doi.org/10.1111/iej.12477

[30] Tomasi C, Bressan E, Corazza B, Mazzoleni S, Stellini E, Lith A. Reliability and reproducibility of linear mandible measurements with the use of a cone-beam computed tomography and two object inclinations. Dentomaxillofac Radiol 2011; 4O(4):244-50. https://doi.org/10.1259/dmfr/17432330 